\title{
Professores em tempos de pandemia: percepções, sentimentos e prática pedagógica
}

\author{
Teachers in pandemic times: perceptions, feelings and pedagogical practice
}

Docentes en tiempos de pandemia: percepciones, sentimientos y práctica pedagógica

\section{Resumo}

Sonia Bessa ${ }^{1}$

Essa investigação é um estudo exploratório com desenho descritivo comparativo com objetivos de analisar sentimentos, percepções e ações pedagógicas dos professores dos anos iniciais do ensino fundamental durante a pandemia da covid 19, averiguar os efeitos do fenômeno pandêmico sob o sistema de educação, descrever como o isolamento afetou o segmento educacional dos anos iniciais em função do acesso aos processos de ensino aprendizagem e prática pedagógica. Foi constituída amostra de 67 professores que atuam nos anos iniciais do ensino fundamental de duas unidades federativas do Brasil (SP e GO). Como instrumento, foi utilizado um questionário on-line via google forms. A percepção e os sentimentos dos docentes frente à experiência com o ensino remoto, foram muito similares perpassando variáveis como idade, sexo, cidade e estado em que reside e redes de ensino em que trabalham. Os participantes partilharam necessidades similares quanto ao apoio financeiro, psicológico e técnico. A priorização do trabalho foi uma realidade para os professores.

Palavras-chave Pandemia; Professores; Ensino-aprendizagem; Prática pedagógica.

\begin{abstract}
This investigation is an exploratory study with a comparative descriptive design aimed at analyzing the feelings, perceptions and pedagogical actions of teachers in the early years of elementary school during the covid pandemic 19, ascertaining the effects of the pandemic phenomenon under the education system, describing how the isolation affected the educational segment of initial years, depending on the access to teaching processes, learning and pedagogical practice. A sample of 67 teachers who work in the early years of elementary school in two federative units in Brazil (SP and GO) was constituted. As an instrument, an online questionnaire was used via google forms. The perception and feelings of the teachers in the face of the experience with remote education, were very similar across variables such as age, sex, city and state where they live and the education networks in which they work. Participants shared similar needs for financial, psychological and technical support. The prioritization of work was a reality for teachers.

\footnotetext{
${ }^{1}$ Doutora em Educação pela Universidade Estadual de Campinas - UNICAMP, Pós-Doutora pela Universidade Federal do Triangulo Mineiro - UFTM. Professora do Departamento de Educação da Universidade Estadual de Goiás. (UEG). Realiza pesquisas em: Educação Matemática, Educação Econômica e Financeira e Formação de Professores. Líder do LIMA/UEG/CNPq - Laboratório Interdisciplinar em Metodologias Ativas. E-mail: soniabessa@gmail.com ORCID: http://orcid.org/0000-0001-9857-6523
} 


\section{QD DEVIR EDUCAÇÃO \\ ISSN: 2526-849X}

\section{Keywords - Pandemic; Teachers; Teaching-learning; Pedagogical practice.}

\section{Resumen}

Esta investigación es un estudio exploratorio con un diseño descriptivo comparativo con el objetivo de analizar los sentimientos, percepciones y acciones pedagógicas de los docentes de la primeros años de la escuela primaria, investigar los efectos del fenómeno pandémico en el sistema educativo, describir cómo el aislamiento afectó al segmento educativo de los primeros años debido al acceso a los procesos de enseñanza, aprendizaje y práctica pedagógica. Se constituyó una muestra de 67 docentes que laboran en los primeros años de la escuela primaria en dos unidades federales de Brasil (SP y GO). Como instrumento se utilizó un cuestionario on-line a través de formularios de google. La percepción y los sentimientos de los profesores sobre la experiencia con la enseñanza a distancia fueron muy similares, permeando variables como la edad, el género, la ciudad y estado en que viven y las redes educativas en las que trabajan. Los participantes compartieron necesidades similares de apoyo financiero, psicológico y técnico. La priorización del trabajo fue una realidad para los docentes.

Palabras clave: Pandemia; Maestros; Enseñanza-aprendizaje; Práctica pedagógica.

\section{Introdução}

No final do ano de 2019, um novo vírus foi identificado em uma região da China, chamada Wuhan. Este vírus foi batizado com o nome de "Covid-19" em fevereiro pela Organização Mundial de Saúde - OMS e no dia 11/03/2020 foi declarado como pandemia. O vírus afeta, principalmente, o sistema respiratório, causando assim uma síndrome aguda respiratória. Inicialmente, o vírus se espalhou de forma rápida pela China e, em poucos meses, se espalhou para todos os continentes, assumindo a característica de Pandemia. O contágio do vírus acontece principalmente pelo ar ou pelo contato pessoal, sendo elas por gotículas de saliva, espirro, tosse e superfícies contaminadas.

Neste ínterim, a pandemia da Covid-19 trouxe ao mundo inúmeras consequências, além dos impactos na economia, na vida social, na organização familiar, ressaltamos aqui as repercussões que esse cenário causou no âmbito educacional. Desde o dia 26 de fevereiro, onde o primeiro caso no país foi registrado e, em 13 de março, quando foi confirmado o primeiro óbito, o Brasil ainda se mostrava incrédulo quanto aos possíveis efeitos que o tal vírus causaria em todas as esferas da sociedade.

De acordo com a folha informativa produzida pela Organização Pan-Americana da Saúde - OPAS (2020), certifica-se que foram confirmados no mundo, milhões de infectados e mortos. A OPAS e a OMS estão prestando apoio técnico ao Brasil e outros países, na 


\section{OO DEVIR EDUCAÇÃO}

ISSN: 2526-849X

preparação e resposta ao surto de COVID-19. No Brasil, já são mais de 520.000 mortos em pouco mais de um ano de pandemia.

Mediante esse flagelo o sistema educacional brasileiro tem enfrentado desafios a fim de garantir acesso à educação para seus estudantes, uma vez que aulas em universidades e em instituições de educação básica foram suspensas. As ações de combate ao coronavírus interromperam as aulas presenciais nas escolas brasileiras, impactando na Educação Básica (Educação Infantil, Ensino Fundamental e Ensino Médio). Em março de 2020, o Ministério da Educação - MEC publicou a portaria 343 autorizando, em caráter excepcional, a substituição das disciplinas presenciais, em andamento, por aulas que utilizem meio e tecnologias de informação e comunicação. Somente na Educação Básica, foram 47,9 milhões de estudantes segundo dados do Instituto Nacional de Pesquisas Educacionais Anísio Teixeira - INEP 2019. As escolas deveriam permanecer fechadas até que a situação se estabilizasse. Após quase dois anos, ainda é incerto o retorno as atividades presenciais em escolas de vários estados brasileiros. Segundo dados do relatório Cenário da exclusão escolar do Brasil da UNICEF (2021) referente ao mês de novembro de 2020, portanto ao final do ano letivo, 5.075.294 crianças e adolescentes de 6 a 17 anos estavam fora da escola ou sem atividades escolares, o que corresponde a 13,9\% dessa parcela da população em todo o Brasil. Essa mudança pode ter impactos em toda uma geração. São crianças dos anos iniciais do ensino fundamental, fase de alfabetização e outras aprendizagens essenciais às demais etapas escolares. Ciclos de alfabetização incompletos podem acarretar reprovações e abandono escolar. O Relatório alerta para a urgência em reabrir as escolas, e mantê-las abertas, em segurança.

Neste novo contexto, professores e toda equipe gestora tiveram que adequar o ensino, fazendo uso de recursos tecnológicos, para dar continuidade às atividades, no entanto, muitos estudantes de comunidades carentes não têm acesso à internet, a infraestrutura não é adequada, faltam recursos técnicos e tecnológicos para dar suporte aos educandos. $\mathrm{O}$ despreparo dos profissionais com as ferramentas digitais inibe e dificulta o processo de ensino e aprendizagem. Em decorrência dessa situação, inúmeros problemas podem ocorrer, tanto com a equipe escolar quanto com alunos e suas famílias, tais como: a evasão escolar, ansiedade e desmotivação dos estudantes e seus responsáveis, preocupações dos professores em manter seus empregos, cumprir os dias letivos, cumprir com êxito os conteúdos prescritos no currículo, bem como ofertar um ensino de qualidade.

Revista Devir Educação, Lavras-MG. Edição Especial, p.183-205, Set./2021. 


\section{OO DEVIR EDUCAÇÃO \\ ISSN: 2526-849X}

Para Lamim, Nascimento e Cordeiro (2020, p. 361) Professores de todo o mundo veem-se frente a um desafio sem precedentes, tendo que buscar respostas urgentes para um problema de abrangência mundial. "Com o isolamento social imposto pela pandemia da COVID-19, [....] os professores foram obrigados a reinventar suas maneiras de dar aula, adequar-se às novas tecnologias e tentar preservar sua saúde mental".

Diante desta situação, como abordam Pereira, Santos e Manenti (2020), torna-se possível visualizar no contexto atual muitas situações de incertezas a respeito da educação, advindas pela pandemia da COVID-19 no cenário educacional, exigindo de forma incisiva que os professores renovem de forma constante a sua docência para que o ensino a distância seja eficiente, mas sem levar em conta os diversos problemas presentes no seu cotidiano, como a falta de requisitos para o seu trabalho, seja estruturalmente ou na sua formação. Mediante isto, os professores devem adequar o seu perfil para se encaixar em uma nova realidade, exigindo ações diferenciadas para atender o que é exigido.

O trabalho do professor aumentou de forma significativa, levando em conta que os professores tiveram que de forma repentina usar da tecnologia integralmente em seu trabalho, usando ferramentas da internet para fazer atividades on-line, bem como trabalhando com materiais físicos para os alunos que não possuem acesso à internet. Por estarem em casa, a grande maioria dos professores teve a carga horária de trabalho aumentada, sem ter um horário específico para começar e terminar. Tudo isso de suas casas com os seus próprios recursos, tendo uma sobrecarga física e emocional. Apesar de todo este trabalho, os professores são usualmente julgados por parte da população que dizem que eles não estão trabalhando, mas mesmo assim recebendo. Para Zaidan e Galvão (2020, p.264) foi uma mudança muito rápida e drástica na rotina dos professores, “[...] que se caracteriza pela penetração insidiosa do trabalho em todos os espaços e momentos de seu cotidiano, não importando que seus empregadores (o governo ou os donos de escola) não lhes tenham garantido estrutura para o teletrabalho".

Por conta disso, Pereira, Santos e Manenti (2020) ressaltam que se torna muito importante se preocupar com as cobranças sofridas pelos profissionais e a saúde mental dos professores, levando em conta que encontram-se em completa incerteza, devido à falta de diretrizes, protocolos e recursos destinados à educação com intuito de promover o acesso ao ensino para as classes mais baixas da sociedade, evidenciando a desigualdade no meio social. Outro fator que impactou psicologicamente o profissional da educação foi o isolamento 


\section{OO DEVIR EDUCAÇÃO}

ISSN: 2526-849X

social, a falta de interação social, a troca de pontos de vista com seus pares e outras pessoas, o que pode contribuir para o surgimento de problemas para a saúde mental, aliados à sobrecarga de trabalho, estresse, ansiedade e cansaço conforme discorre Hackenhaar e Grandi (2020), ao referir-se à saúde mental e ao equilíbrio.

O primeiro informe de pesquisa realizada pela fundação Carlos Chagas em parceria com a Organização das Nações Unidas para a Educação a Ciência e a Cultura - UNESCO "Educação Escolar em Tempos de Pandemia" com professores de todas as regiões brasileiras com o objetivo de verificar como as professoras e os professores das redes públicas e privadas estão desenvolvendo suas atividades, constatou que o trabalho pedagógico mudou e aumentou significativamente com destaque para as atividades que envolvem a interface e/ou interação digital. O uso de materiais digitais via redes sociais virou a principal estratégia pedagógica para a maioria dos professores do Brasil. Conforme aponta Rambo (2020), o momento "póspandemia" fará com que os profissionais da educação e os estudantes manifestem-se diferentes, seja do ponto de vista comportamental e psicológico, de forma a subentender assim, a certeza dos impactos da Covid-19 no sistema educacional.

Frente ao que já foi apresentado, Silva, Petry e Uggioni (2020, p. 22) afirmam que fazem parte das insuficiências escolares no Brasil, a ausência de "formação específica para professores e o entendimento por parte da sociedade e o precário acesso da comunidade escolar a recursos tecnológicos, como computadores e internet de qualidade", revelando, deste modo, a escassez da condição estrutural da educação no país, em especial sob a ótica deste fenômeno pandêmico. Nesta conjuntura, as hipóteses iniciais da presente pesquisa pressupõem que: I - $\mathrm{O}$ isolamento social tem afetado o bem-estar e a saúde mental dos docentes, com predomínio de ansiedade, estresse, depressão, sobrecarga de trabalho e dificuldades de conciliar a vida profissional, social e familiar; II - A dinâmica de trabalho dos professores e estudantes participantes da rede pública de ensino tem expressado limitações, em seu sentido estrutural; III - A aprendizagem dos estudantes quanto aos conteúdos escolares durante a pandemia diminuiu e ficou limitada aos recursos tecnológicos daqueles que o possuem; IV - A experiência com o ensino remoto pode ser avaliada como "ruim" pelos docentes e representa um desafio a ser superado.

Uma das alternativas funcionais de se corroborar a minimização dos problemas enfrentados pela escola, neste cenário pandêmico, refere-se à existência de pesquisas científicas. Isto porque a "ciência" e, logo, a "ação científica", cooperam com avanços de 


\section{QD DEVIR EDUCAÇÃO \\ ISSN: 2526-849X}

distintos bojos de uma sociedade, pois, assim como realçam Lima e Viana (2017), as pesquisas são quesitos essenciais ao desenvolvimento estrutural favorável de uma nação. Conforme sustentam Fazenda, Tavares e Godoy (2015), o trabalho científico, quando alicerçado nos princípios da criticidade, autonomia e emancipação, preza por oferecer um olhar mais atento e sensível à realidade, sendo vivenciada de forma a constituir um acervo organizacional do fenômeno, produzir conhecimento e, assim, valorizar o campo em investigação.

Por isto, a relevância deste trabalho, em coletar, descrever e analisar as perspectivas e subjetividades frente a esse fenômeno pandêmico, que ainda não se sabe quando terá fim, aos docentes e a estrutura educacional, com a finalidade em oferecer um aparato do cenário sendo vivenciado, neste contexto, à comunidade educacional. Nesse contexto esse relato tem como objetivos analisar sentimentos, percepções e ações pedagógicas dos professores dos anos iniciais do ensino fundamental, averiguar os efeitos do fenômeno pandêmico sob o sistema de educação, descrever como o isolamento afetou o segmento educacional dos anos iniciais em função do acesso aos processos de ensino aprendizagem e prática pedagógica.

\section{Metodologia}

Neste cenário de rápida transformação e alta incerteza, torna-se necessário compreender como os (as) professores (as) estão se sentindo, como tem sido a sua atuação profissional, a utilização das ferramentas tecnológicas, seus anseios e demandas de apoio. Assim, foi proposto a professores do Município de Formosa-GO e da região metropolitana de São Paulo-SP, um instrumento com o objetivo de analisar sentimentos, percepções e práticas pedagógicas de professores da educação infantil e dos anos iniciais do ensino fundamental frente à pandemia da Covid 19.

Essa investigação é um estudo exploratório com desenho descritivo comparativo. A fim de compor a amostra, foram selecionados, de forma aleatória, 67 professores que atuem na educação infantil e nos anos iniciais do ensino fundamental de duas cidades de dois estados (Goiás e São Paulo) e de dois tipos de escolas: Municipais e estaduais. Em FormosaGO foram professores de três escolas municipais e em São Paulo-SP uma_escola municipal e duas estaduais. 51 professores atuam em escolas municipais e 17 em escolas estaduais das duas cidades. 24 atuam nos anos iniciais, 20 na educação infantil e 17 atuam nas duas etapas 
simultaneamente. A tabela 1 apresenta a distribuição dos professores por unidade federativa, gênero e idade.

Tabela 1 - Distribuição dos participantes por gênero, unidade federativa e idade

\begin{tabular}{|c|c|c|c|c|c|}
\hline \multirow{2}{*}{\multicolumn{2}{|c|}{ Residência }} & & \multicolumn{2}{|c|}{ sexo } & \multirow[b]{2}{*}{ Total } \\
\hline & & & Masculino & Feminino & \\
\hline \multirow{4}{*}{\multicolumn{2}{|c|}{ Formosa-GO Idade }} & 18 a 29 anos & 1 & 5 & 6 \\
\hline & & 30 a 39 anos & 5 & 13 & 18 \\
\hline & & 40 a 49 anos & - & 9 & 9 \\
\hline & & Mais de 50 anos & 1 & 2 & 3 \\
\hline \multirow[t]{3}{*}{ São Paulo-SP } & Idade & 30 a 39 anos & - & 7 & 7 \\
\hline & & 40 a 49 anos & 1 & 12 & 13 \\
\hline & & Mais de 50 anos & 1 & 10 & 11 \\
\hline Total & Total & & 9 & 58 & 67 \\
\hline
\end{tabular}

Fonte: Dados organizados pela autora.

Como instrumento, foi utilizado um questionário on-line, com abordagem que atende os objetivos propostos: o impacto do isolamento quanto aos aspectos psicológicos, o acesso à tecnologia e dinâmica de trabalho dos professores e os caminhos alternativos para a docência no contexto da pandemia.

A fim de facilitar uma maior participação de professores e manter o isolamento social, o questionário foi enviado aos professores via whatsapp e e-mail, por meio do aplicativo google forms. Esse é um aplicativo do Google de gerenciamento de pesquisas lançado pelo Google. Os usuários podem usar o Google Forms para pesquisar e coletar informações sobre outras pessoas e também podem ser usados para questionários e formulários de registro. $\mathrm{O}$ Google Forms possui recursos de colaboração e compartilhamento para vários usuários. Uma vez concluído o questionário, o passo seguinte foi divulgar o instrumento em escolas do município de Formosa-GO e algumas da cidade de São Paulo-SP, cuja pesquisadora mantinha contato. Foi feito um contato inicial com os diretores e solicitado a autorização para envio dos questionários para os professores da educação infantil e dos anos iniciais do ensino fundamental. Após a autorização foram enviados entre as duas últimas semanas de outubro de 2020, 114 questionários e destes 67 professores responderam.

\section{Resultados e discussão}




\section{QD DEVIR EDUCAÇÃO \\ ISSN: 2526-849X}

Após a aplicação do instrumento, os dados foram analisados com base na caracterização geral dos participantes e nas diferenças existentes de acordo com as variáveis incluídas. Os dados foram organizados em uma matriz por variáveis e submetidos a análises estatísticas de tipo descritivo e inferencial; paramétrico e não paramétrico. $\mathrm{O}$ programa estatístico SPSS para Windows versão 22.0 (IBM/SPSS) deu suporte para as análises. Para todos os tratamentos, adotou-se um nível de significância de 0,05.

Foi utilizado o teste Shapiro wilk para verificar a pressuposição de normalidade na distribuição da amostra e o teste T Students para amostras independentes nas variáveis de controle: gênero e unidade federativa a que pertencem os professores e o Mann-Whitney, para os dados não paramétricos. A ANOVA unidirecional permitiu observar a existência de diferenças significativas quanto às variáveis idade, etapas e rede de ensino em que atuam os professores. Para os dados não paramétricos, foi utilizado o teste Kruskal-Wallis.

Os resultados foram organizados em sete tópicos a fim de facilitar a compreensão do leitor: 1. Preparo para o ensino no contexto da pandemia, 2. Sentimentos do professor frente à pandemia, 3. Objetos de dedicação durante a pandemia, 4. Autoavaliação, 5. Apoio, 6. A aprendizagem dos estudantes e 7. As tarefas escolares.

\section{Preparo para o ensino no contexto da pandemia}

Os dados apresentados na tabela 2 demonstram que grande parcela dos professores reconhece que não se encontra capacitada para trabalhar remotamente, confirmando assim, as indulgências estruturais escolares para com as Tecnologias de Informação e Comunicação TICS. Verifica-se que quase $80 \%$ dos professores sentem-se pouco preparados para o trabalho remoto e tem recebido pouca formação técnica para o trabalho.

Tabela 2 - Sentimentos referente ao "preparo" para se ensinar de forma remota.

\begin{tabular}{lcc}
\hline & Frequência & Porcentagem \\
\hline Sinto-me pouco preparado (a) & 53 & $79,1 \%$ \\
Sinto-me nada preparado (a) & 9 & $13,4 \%$ \\
Sinto-me muito preparado (a) & 3 & $4,5 \%$ \\
Sinto-me totalmente preparado (a) & 2 & $3,0 \%$ \\
Total & 67 & $100,0 \%$ \\
\hline
\end{tabular}

Fonte: Dados organizados pela autora.

Revista Devir Educação, Lavras-MG. Edição Especial, p.183-205, Set./2021. 


\section{QD DEVIR EDUCAÇÃO \\ ISSN: 2526-849X}

A pandemia pegou os profissionais da educação de surpresa e, muito rapidamente, os mesmos tiveram que se reinventar quanto ao ensino remoto. Esta realidade não foi exclusiva dos professores de Formosa, ou de São Paulo que participaram desta investigação. Para Macedo (2021), a eclosão da pandemia de coronavírus em 2020 e o fechamento das escolas, foi a ocasião propícia para ficar em evidência os mecanismos de criação e reprodução das desigualdades, acentuando a presença de diversos operadores de diferenciação social e aumentando as distâncias educacionais entre escolas públicas e privadas, ricos e pobres, agrega-se às desigualdades educacionais e sociais as desigualdades digitais. Corroborando essa perspectiva, Silva (2020) salienta que vivemos em uma era digital na qual a tecnologia se faz presente por meios de comunicação e aplicativos, contudo a formação docente é precária e insuficiente.

A fim de verificar diferenças significativas quanto à idade, redes de ensino e etapas de atuação, foi utilizado o teste estatístico ANOVA unidirecional e constatou-se que não houve diferença significativa $\mathrm{p}>0,05$ em nenhuma dessas variáveis. O teste T Students mostrou que as variáveis gênero e unidade federativa também não têm diferença significativa. Conclui-se, pois, que professores de são Paulo e Formosa, de ambos os sexos, que atuam na educação infantil e nos iniciais, com idades diferentes, das redes municipais ou estaduais, sentem-se despreparados para a súbita mudança da forma presencial para a forma on-line. Como destaca Macedo (2021) o fosso de desigualdades sociais e digitais entre os estudantes das escolas públicas que já era acentuado se tornou uma questão central nesse período de crise e revela a ausência de políticas educacionais focadas em garantir a conectividade e o direito à educação. "Deixados à própria sorte, coube às diversas escolas públicas, famílias e professores encontrarem soluções criativas e paliativas para tentar manter a conexão com seus estudantes que não tinham acesso à internet e a equipamentos digitais adequados" (MACEDO 2021, p. 264).

Foi indagado aos professores quais ações eles consideram prioritárias para garantir a qualidade mínima dos processos de ensino e aprendizagem. Quatro ações se destacaram: ofertas de aulas virtuais ou on-line (94\%) e envio de material pedagógico aos estudantes (91\%), contato direto com as famílias dos estudantes $(80,6 \%)$ e adaptação do currículo escolar $(77,6 \%)$ foram as ações mais frequentes professores entrevistados. Os professores dispõem aulas gravadas e plataformas on-line para que os alunos possam desenvolver as atividades propostas. Muitas atividades que estavam previstas no currículo acabaram sendo esquecidas, e 


\section{QD DEVIR EDUCAÇÃO \\ ISSN: 2526-849X}

muitas escolas fizeram uma adaptação do seu currículo para continuar os trabalhos. Para Honorato (2021) o currículo precisa ser cumprido e esta deve ser a primeira preocupação dos gestores educacionais, mesmo que pelo ensino remoto, uma vez que o currículo previsto para uma escola presencial não se alinha com a metodologia de uma educação a distância. Esse autor alerta que em uma situação improdutiva com conteúdo massificados priva os estudantes da avaliação do ensino-aprendizagem.

Nas três escolas de Formosa-GO, objeto de estudo dessa investigação, os professores vão até a escola num determinado período e disponibilizam materiais pedagógicos para os estudantes, uma vez que muitos estudantes não possuem acesso à internet, nem mesmo pelo celular, para acompanhar as aulas. Verifica-se um esforço dos professores em tentar adaptar o currículo ao contexto remoto das aulas. Como destacam Feltrin e Batista (2020, p. 1024) a realidade imposta pela pandemia, foi uma condição para pensar a readaptação às novas formas de ensinar/aprender, e para continuar a ensinar, tornou-se mais do que nunca necessário aprender, mas, as autoras alertam que reinventar a docência requer cuidado "[...] para que não se perca o humano nas relações de ensino. A fala, a proximidade, o acolhimento às individualidades, a valorização do humano levanta-se como bandeiras centrais à reinvenção docente. [...] o olhar para a diferença deve permanecer e se reinventar também”. Verifica-se que houve uma predisposição $(80,6 \%)$ dos professores em manterem contato com os pais mesmo utilizando unicamente o aplicativo do WhatsApp como foi o caso das escolas goianas.

\section{Sentimentos do professor frente à pandemia}

Em relação às respostas de como os professores têm se sentido no decorrer da pandemia, foi possível verificar que o maior percentual das respostas se concentra em dois sentimentos: "ansiedade" e "sobrecarga de trabalho". Quase 70\% dos professores fizeram menção a esses dois sentimentos. Também destacaram outros sentimentos como cansaço $62,7 \%$, estresse $34,3 \%$, depressão $28,4 \%$; solidão $22 \%$ e outros $15 \%$ estão se sentindo entediados. Esses sentimentos revelam que os professores foram atingidos psicologicamente pelo isolamento social, pela incerteza e pelas mudanças repentinas decorrentes da pandemia. $\mathrm{O}$ excesso de atividades, a falta de reconhecimento e a urgência de aprender novas metodologias de ensino, aliado ao ambiente de insegurança sobre o futuro causou uma sobrecarga de estresse nos professores. 


\section{QD DEVIR EDUCAÇÃO \\ ISSN: 2526-849X}

Nesta perspectiva Dias e Pinto (2020) fundamentam que os secretários da Educação e gestores necessitam prestar apoio e refletirem sobre a saúde mental de todos, pois assim como milhares de estudantes foram prejudicados, os professores também se encontram fragilizados. Se os docentes estiverem exaustos mental e fisicamente, bem como aponta a pesquisa, não poderão ajudar a si ou aos estudantes. Macedo (2021) faz menção ao impacto da pandemia quanto aos aspectos econômicos, psicológicos, sociais e de saúde das famílias e dos professores em particular, a estes últimos agregaram-se elementos estressantes como a "[...] manutenção do interesse dos estudantes em relação aos estudos, bem como a solidão e as saudades dos colegas".

Dentre os 67 docentes participantes da pesquisa, apenas 12 (17,9\%) precisaram se afastar dos trabalhos desenvolvidos no ensino remoto por questões de saúde, ao passo que 55 $(82,1 \%)$ certificaram que não precisaram ainda adotar tal medida. Nesta perspectiva, ao serem comparadas as informações apresentadas pelos docentes na questão anterior, que de forma acentuada estão: "ansiosos (as)", "estressados (as)", "sobrecarregados (as)", "cansados (as)", estes sustentam que, neste período, as questões de saúde não foram empecilho para trabalharem, mesmo sob forte carga emocional. Em estudos da FCC (2020), contatou-se que os sentimentos dos professores quanto à pandemia estão associados ao volume de atividades e ao excesso de pressão como ansiedade, sobrecarga, cansaço e estresse que impactam a condição emocional dos educadores. "Esse conjunto de sentimentos expressa-se com mais frequência entre as professoras. Um segundo grupo de sentimentos negativos, como frustração, tédio, depressão e solidão, mais associados a fatores individuais e expressos de modo mais equilibrado entre homens e mulheres". (p.65).

Neste sentido, torna-se necessário que os (as) docentes considerem não apenas as questões de saúde física, mas também as questões de saúde mental neste momento atípico. Alguns transtornos e doenças os quais os profissionais da educação estão desenvolvendo estão relacionados com as determinações diretas advindas dos novos formatos e condições trabalhistas neste período de pandemia. Como afirma Moreira e Rodrigues (2018), quando a saúde mental é prejudicada, consequentemente, a dimensão física também será afetada.

Foi solicitado aos professores que descrevessem o seu nível de preocupação com sua saúde física, mental, a saúde de seus familiares e outras eventuais preocupações. O Gráfico 2 apresenta estes níveis. Somente $6 \%$ estão tranquilos quanto a sua saúde física e mental, o 


\section{OO DEVIR EDUCAÇÃO \\ ISSN: 2526-849X}

maior nível de preocupação dos professores é com a sua saúde mental e a saúde da sua família.

A maioria dos educadores do Brasil são mulheres, índices refletidos nesse estudo com $86,6 \%$ da amostra. Silva et al. (2020, p. 158) alega que a responsabilização das mulheres pelas atividades do cuidado está presente na história da sociedade patriarcal. "as medidas tomadas para garantir o isolamento social e evitar o aumento do número de casos resultaram na sobrecarga das mulheres, já marcadas na sociedade moderna pelas múltiplas jornadas". Na perspectiva desses autores a garantia da sobrevivência tornou-se a base da sobrecarga e impactou a saúde mental das mulheres. Corroborando essa perspectiva o relatório ONU mulheres 2020 disserta que as mulheres continuam sendo as mais afetadas pelo trabalho nãoremunerado, principalmente em tempos de crise. "Devido à saturação dos sistemas de saúde e ao fechamento das escolas, as tarefas de cuidado recaem principalmente sobre as mulheres, que, em geral, têm a responsabilidade de cuidar de familiares doentes, pessoas idosas e crianças" (ONU MULHERES, 2020, p.1).

A saúde da família, sua própria saúde física e mental são fortes motivos de preocupação dos professores participantes como pode ser observado no gráfico 1 .

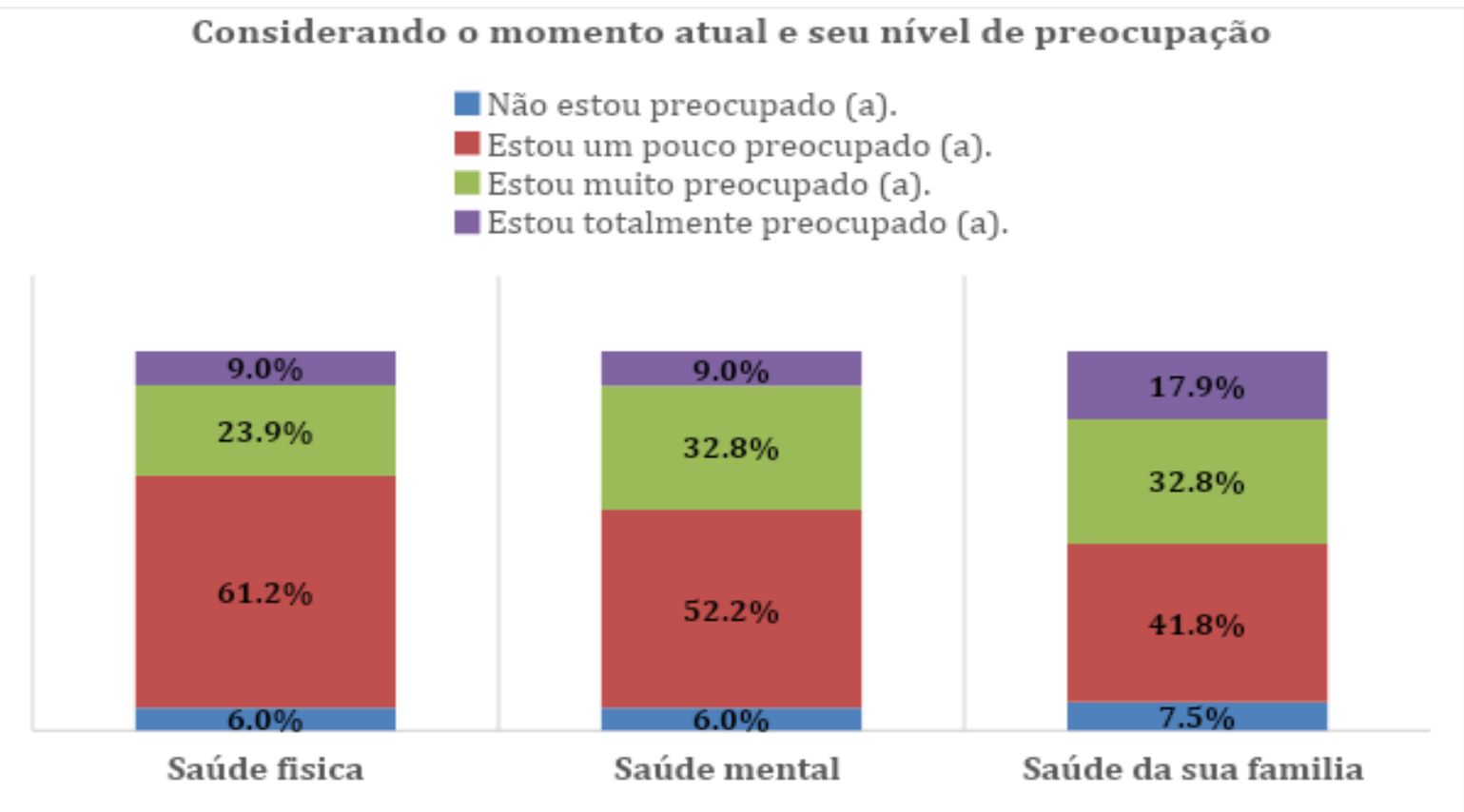

Gráfico 1 - Níveis de preocupações dos docentes com relação à saúde mental, física e familiar.

O nível de preocupação dos (as) professores (as) de São Paulo apresentou diferença significativa quanto à saúde física em relação aos (as) professores (as) de Formosa. $\mathrm{O}$ teste $\mathrm{t}$ 


\section{OO DEVIR EDUCAÇÃO}

ISSN: 2526-849X

Students mostrou que os professores de SP estão mais preocupados com sua saúde que os de Formosa $(\mathrm{t}(65)=-2,388 ; \mathrm{p}<0,02)$. É possível que a inevitável aglomeração de uma cidade do porte de São Paulo seja uma dessas causas de preocupação, para si e para os seus familiares. Para Pereira Santos e Manenti (2020), o cuidado com a saúde mental dos educadores precisa ser levado a sério, e tomadas as medidas para as atuais condições de trabalho em formato home office, e estratégias adequadas para o retorno das aulas presenciais nas escolas. Segundo esses autores ações e diligências preventivas e promotoras de saúde podem reduzir as implicações psicológicas da pandemia.

Quanto ao gênero, idade, redes de ensino a que pertencem e etapas de atuação dos participantes, não foi verificada diferença significativa. Os resultados indicaram que não importa em qual rede de ensino ou etapa de ensino atue, homem ou mulher, mais ou menos jovem, todos estão muito preocupados com a sua saúde física e mental e quanto maior for a cidade em que moram, aumenta mais a preocupação. Tal nível de preocupação gera estresse, ansiedade e impacta diretamente a atuação profissional do (a) professor (a), que de um momento para o outro viu-se obrigado a dominar tanto os conteúdos quanto as ferramentas tecnológicas, de forma criativa e envolvente. Conforme descrevem Feltrin e Batista (2020), na situação de pandemia não existe mais separação entre o mundo do trabalho e o mundo pessoal e se o professor esquecer as ferramentas M-learning estão aí para lembrá-los.

\section{Objetos de dedicação durante a pandemia}

Buscou-se averiguar quais atividades cotidianas os (as) professores (as) passaram a dedicar mais tempo durante a pandemia. Destacaram-se atividades domésticas, da escola, capacitação profissional, vida pessoal e familiar. Muitos docentes, durante a pandemia, tiveram que readequar o ensino, desempenhando diversas atividades neste período. Os professores de todas as áreas e níveis de ensino tiveram que adaptar seu trabalho para ser feito de casa com auxílio das tecnologias, 98,5\% dos docentes alegaram que dispensaram um tempo maior para trabalhar de casa nas atividades da escola, e 80,6\% buscaram algum tipo de capacitação, como cursos on-line, livros, referências bibliográficas, sites de universidade e outros. Mesmo com essa sobrecarga de trabalho, a organização familiar e as atividades do lar continuam solicitando atenção dos (as) professores (as) numa proporção de 67,2 e 61,2\% respectivamente. Os filhos, nesse turbilhão de afazeres, foram outra preocupação constante dos (as) professores (as), e 52,2\% reconhecem que se dedicam a apoiar os filhos nas tarefas 


\section{OO DEVIR EDUCAÇÃO}

ISSN: 2526-849X

escolares. O primeiro olhar do (a) professor (a) foi para o trabalho, seguido do aspecto familiar. Para Palu (2020, p. 79), sem capacitação profissional, o trabalho docente duplicou ou triplicou com o início das aulas remotas. Para essa autora "Os educadores se encontram sobrecarregados e atarefados, pois além da participação na formação para trabalhar com novas ferramentas, passaram a ter que alimentar plataformas on-line [...], subentendendo assim, o aumento no trabalho dos docentes neste cenário pandêmico".

Não foi verificada diferença significativa quanto às variáveis, gênero, idade, etapas de ensino, rede escolar atual e unidade federativa, a priorização do trabalho foi uma realidade para professores de todos os níveis, etapa de ensino, unidade federativa ou idade.

Para Lamim, Nacimento e Cordeiro (2020, p. 361) “[...] os desafios em sala de aula são imensos o novo cenário nos faz refletir no desafio imposto aos professores do mundo todo em dar continuidade a um trabalho que tem na figura do professor um agente de esperança e doação para garantir a continuidade do percurso educativo de milhares de alunos”.

A percepção dos dias difíceis é uma realidade presente no discurso dos professores, contudo, existe determinação mediante o enorme desafio, de ser professor em tempos de pandemia. Esses resultados acentuam o compromisso, a resiliência e a consciência profissional dos professores.

\section{Autoavaliação}

Houve a necessidade de averiguar como os professores se autoavaliam na execução desse novo formato de trabalho, em que as aulas presenciais foram substituídas por aulas em meio digitais e remotos.

Constatou-se que 49,3\% dos docentes acreditam estar em um bom caminho, tem uma avaliação positiva do seu trabalho, e outros 37,3\% o consideram razoável. Essas afirmações denotam que, apesar de todas as vicissitudes da novidade de trabalho, os professores ainda se sentem realizando um bom trabalho. Mesmo diante de tantos desafios enfrentados pelos/pelas docentes, estes ainda mostram otimismo quanto sua atuação neste momento atípico, e somente $13,4 \%$ estão frustrados alegando que seu trabalho é ruim ou péssimo. Pressupõe-se que, mesmo com ausência de capacitação profissional, os professores percebem que estão atendendo às novas formas de atuar, exigidas pela instituição de ensino e pela circunstância do momento. Para Schneiders (2020, p.212), esse novo contexto promoveu alguns fatores como:

Revista Devir Educação, Lavras-MG. Edição Especial, p.183-205, Set./2021. 


\section{QD DEVIR EDUCAÇÃO \\ ISSN: 2526-849X}

[...] invasão de privacidade, preenchimento de documentação, indecisão acerca dos temas, conceitos e conteúdos a se trabalhar, sobrecarga horária, incerteza sobre o alcance dos objetivos educacionais, precariedade das ferramentas de trabalho, aliados com o distanciamento social, debilitou a saúde mental dos professores.

Conforme Gotti et al. (2020) fatores como incerteza, medo, insegurança e ansiedade, foram fortemente evocados pela pandemia. Contudo, essa investigação com professores dos municípios de Formosa e de São Paulo, constatou a resiliência dos professores em ainda manterem o otimismo frente às adversidades.

Como reforça Oliveira et al. (2020), os professores têm buscado inúmeras formas para atender as exigências para a continuação das aulas, por mais que às vezes possam faltar as ferramentas mais apropriadas ou precise dividir com alguém, eles estão empenhando-se, mesmo com todas adversidades para continuar com o ensino, "Novas estratégias de transmissão de conteúdo, aulas on-line, aulas gravadas, planos de aula diferenciados, plataformas digitais permitiram a conexão imediata entre escola e família" (HACKENHAAR; GRANDI, 2020, p. 58).

Vale ponderar que a autoavaliação do/da docente frente à experiência com o ensino remoto, foi um aspecto que se apresentou homogêneo mediante todas as variáveis, sem diferença significativa, ou seja, variáveis que perpassam a idade, sexo, cidade e estado em que reside, rede de ensino em que trabalham, etapas de ensino com que atuaram ou atuam não tiveram diferença significativa.

\section{Apoio}

Foi solicitado aos professores que assinalassem o tipo de apoio que consideram importante receber nesse momento de pandemia. Três tipos de apoio se destacaram, o apoio financeiro, um quarto $(25,4 \%)$ dos participantes expressaram preocupação com sua segurança financeira e como manter a sua família nesse período da pandemia, em consequência dessa primeira preocupação, surge a segunda, relacionada à capacitação profissional para saber lidar com os estudantes nas aulas on-line (19,4\%). Apoio para conciliar as atividades domésticas e o trabalho também teve um percentual expressivo de 14,9\% dos participantes e apoio psicológico e emocional teve um percentual baixo com apenas 10,4\%. Ao iniciar essa 


\section{OO DEVIR EDUCAÇÃO}

ISSN: 2526-849X

investigação, uma das hipóteses levantadas foi que esse seria o principal apoio requerido pelos professores, contudo a questão financeira e o apoio técnico se sobressaíram, a ausência dos mesmos pode redundar em problemas emocionais e psicológicos.

A fim de verificar o índice de significância para as variáveis de controle, foi feito o teste t Students (gênero e unidade federativa) e a ANOVA unidirecional (idade, etapas de ensino, rede de ensino) e não foi verificada diferença significativa $p<0,05$ em nenhuma dessas variáveis, ou seja, a amostra partilha necessidades similares independente de gênero idade, etapas ou rede de ensino e unidade federativa, quanto ao apoio financeiro, técnico e psicológico.

Um fator preocupante no contexto da pandemia do covid-19 é a sobrecarga de trabalho do (a) professor (a) e o apoio de qualquer natureza pode dar uma melhor qualidade de vida para eles. o trabalho do (a) professor (a) é ligado diretamente com o contato, logo, durante o isolamento social, o (a) professor (a) perdeu esse contato, tendo que suportar a tensão em se acostumar e usar as ferramentas digitais e a elaboração de trabalhos que possam incentivar os estudantes. O contexto educacional, tanto dos professores como dos alunos, foi modificado de forma significativa, e eles tiveram que se adaptar rapidamente e realizar atividades que antes eram feitas na sala de aula e agora tiveram que fazer isso das suas próprias casas.

Foi verificada diferença significativa na variável unidade federativa. O teste t Students $(\mathrm{t}(65)=4,156 ; \mathrm{p}<0,000)$, assim $81 \%$ dos professores de São Paulo reconheceram que estão recebendo algum tipo de formação e somente 35\% dos professores de Formosa. O estado de São Paulo, na categoria de estado mais rico da federação, teve mais iniciativas na formação dos professores, $81 \%$ dos professores paulistas e 35\% dos goianos receberam algum tipo de formação para o ambiente virtual.

\section{A aprendizagem dos estudantes}

A percepção dos (as) professores (as) quanto à aprendizagem dos estudantes foi bem variada. 29,9\% responderam que a aprendizagem aumentou, um número grande de professores $38,8 \%$ alegou que não houve mudança, a aprendizagem remota permaneceu igual a presencial. 10,4\% acharam que diminuiu e 20,9\% não souberam informar. É possível que esses últimos ainda não tenham analisado pormenorizadamente essa questão, ou não tenham feito avaliação, ou esta não permitiu inferir se houve ou não evolução. Conclui-se que a percepção dos docentes quanto à aprendizagem dos estudantes é positiva, para quase $70 \%$ dos 


\section{QD DEVIR EDUCAÇÃO \\ ISSN: 2526-849X}

entrevistados, a aprendizagem aumentou ou permaneceu a mesma. Uma investigação pertinente seria ouvir os pais e os estudantes.

Essa percepção positiva pode ser resultado, do anseio dos professores a sua busca contínua de caminhos para atingir uma melhor qualidade de ensino-aprendizagem. Honorato (2021) disserta que a pandemia mostrou a transformação dos sistemas educacionais para se adaptar as escolas fechadas e ao distanciamento social e procurar solução para a aprendizagem dos estudantes, contudo esse autor alerta para soluções paliativas e improvisadas que podem adiar o problema e colocar no ombro do professor, estudante e família um ônus de continuar o ensino num ambiente não apropriado e que não atende aos aspectos tecnológicos de um ensino remoto, sob o prejuízo de não atingir a qualidade da aprendizagem do estudante.

Foi analisada a percepção dos professores quanto a aprendizagem dos estudantes considerando o gênero dos participantes. A fim de verificar a significância quanto ao gênero foi feito o teste de Levene e este indicou que a amostra não tinha uma distribuição normal ou homogênea, assim optou-se pelo teste não paramétrico de Mann-Whitney e este mostrou que existe diferença na percepção de aprendizagem dos estudantes $(U=158,000 ; p<0,04)$ para as mulheres a aprendizagem dos estudantes aumentou 55,6\%, e na percepção masculina essa se manteve estável, assim nessa variável verificou-se diferença significativa $p<0,05$.

Também foi verificada diferença significativa quanto à unidade federativa ( $U$ = 365,000; p<0,001). Na percepção dos docentes de Formosa, a aprendizagem dos estudantes aumentou ou permaneceu da mesma forma, já os paulistanos não sabem informar ou acham que não mudou, apresentaram incerteza mediante essa questão.

A idade dos participantes também influenciou a percepção quanto à aprendizagem dos estudantes. A ANOVA unidirecional $[\mathrm{F}(3,63)=4,322$ : $\mathrm{p}<0,008]$ mostrou que existe diferença significativa. Os professores de 30 a 39 anos admitem que a aprendizagem dos estudantes aumentou ou permaneceu a mesma. As variáveis rede e etapas de ensino não apresentaram diferença significativa.

\section{Tarefas}

Foi solicitado aos (as) professores (as) que descrevessem a frequência das tarefas solicitadas. $47,8 \%$ afirmaram que a maioria dos estudantes faz as tarefas solicitadas, $28,4 \%$ 


\section{QD DEVIR EDUCAÇÃO \\ ISSN: 2526-849X}

responderam que somente uma minoria faz as tarefas, $16,4 \%$ disseram que somente a metade dos estudantes e 7,5\% disseram que ninguém faz tarefas.

Verificou-se diferença significativa quanto aos moradores de São Paulo e Formosa, o teste $\mathrm{t}$ Students $(\mathrm{t}(65)=6,228 ; \mathrm{p}<0,000)$. Os formosenses alegaram que a maioria $(84 \%)$, ou quase todos os estudantes, fazeram as tarefas, e os professores de São Paulo a resposta foi o contrário, alegando que somente 15\%. A incerteza dos docentes paulistanos quanto à aprendizagem dos estudantes refletiu-se nessa questão das tarefas, se as tarefas não chegam aos estudantes, se a maioria não faz, não temos como saber se está havendo ou não aprendizagem. Por que estudantes de uma cidade pequena e interiorana foram mais eficientes na execução das tarefas? Quais as limitações dos estudantes da cidade de São Paulo? Essas indagações, embora importantes, não foram contempladas nesse estudo.

A idade também apresentou diferença significativa $[F(3,63)=4,322: \mathrm{p}<0,000]$ quanto à execução das tarefas. A ANOVA unidirecional e o Post-Hoc REGWQ mostraram que os (as) professores (as) com idade entre 30 e 39 anos assinalaram que a maioria ou quase todos os estudantes fazem as tarefas. Esse é o mesmo grupo que afirmou que a aprendizagem dos estudantes aumentou ou permaneceu a mesma. Verifica-se que, para esse grupo em especial, a aprendizagem está relacionada diretamente à execução das tarefas solicitadas. As variáveis etapas ou redes de ensino e o gênero não tiveram diferenças significativas.

Quanto à periodicidade de envio de atividades às turmas, 80,6\% dos professores disseram que enviam atividades diariamente, $16,4 \%$ semanalmente e $3 \%$ quinzenalmente. A fim de verificar a significância quanto ao gênero, foi feito o teste de Levene e este indicou que a amostra não tinha uma distribuição normal, $\mathrm{p}<0,05$ assim optou-se pelo teste não paramétrico de Mann-Whitney. Foi verificada diferença significativa quanto ao gênero, o teste de Mann Whitney ( $\mathrm{U}=183,000$ : p<0,003) mostrou que 90\% das mulheres enviam conteúdos diariamente, o mesmo não acontece com os homens que enviam preferencialmente semanal ou quinzenalmente. O envio diário de tarefas certamente sobrecarrega esse grupo que já tem um número de tarefas superior ao assumir a maior parte das tarefas do lar e da família. Segundo dados da FCC (2020), a participação majoritária de mulheres na docência na educação básica é uma realidade histórica. Ao agregar educação e cuidado, em especial nas etapas iniciais, a presença delas chega a 97,5\% nas creches (dados Sinopse Censo da Educação Básica 2019), na medida em que se avança nas etapas de ensino, a presença feminina diminui, ainda que no Ensino médio elas representem $58 \%$. 


\section{OO DEVIR EDUCAÇÃO}

ISSN: 2526-849X

As redes de ensino municipal e estadual tiveram diferença significativa quanto à periodicidade de envio de conteúdo para os estudantes, foi o que mostrou o teste KruskalWallis $\left[\mathrm{x}^{2}(2)=17,737 ; \mathrm{p}<0,000\right]$. As escolas municipais enviam diariamente tarefas e conteúdo para os estudantes, o mesmo não foi verificado nas escolas estaduais.

\section{Considerações finais}

De início, cabe expor que o objetivo central desta pesquisa foi alcançado, pois foi possível averiguar os impactos do fenômeno pandêmico sobre o sistema de educação na população investigada. A análise das respostas confirma duas hipóteses iniciais do estudo, sendo estas: a de que o isolamento social e a mudança abrupta de atividade tem afetado o bem-estar da saúde mental dos docentes e que a aprendizagem dos estudantes durante a pandemia tem manifestado uma diminuição significativa. Estes dados sustentam a perspectiva de que este momento pandêmico acentuou as dificuldades que o sistema de educação brasileiro já enfrentava, como a: desvalorização docente, o despreparo estrutural escolar e o aumento da desigualdade. "Durante a pandemia, as diferenças por sexo e cor/raça presentes na educação, tanto nas perspectivas dos alunos como na de docentes, são mantidas e as desigualdades podem ser ampliadas" (FCC 2020, p. 29).

No entanto, a terceira hipótese inicial deste trabalho não foi constatada, pois a maioria dos professores avaliou a experiência com o ensino remoto como "boa". Este fator chamou atenção, pois mesmo sendo observada a ausência de capacitação, dificuldades de acesso, decaimento da aprendizagem discente e até um quantitativo de professores que tiveram que se afastar do trabalho durante a pandemia, estes foram capazes de ponderar que este formato digital assume-se como favorável à sua atuação, revelando, assim, um otimismo, mesmo com este fenômeno atípico.

Os dados indicaram que a maioria dos (as) professores (as) se sentia, além de despreparados com este modelo, mas também ansiosos, sobrecarregados, cansados, estressados e até depressivos com relação à pandemia. A respeito do nível de preocupação com a saúde física, mental e familiar, verificou-se que são poucos os que se sentem tranquilos com estes fatores e aqui, cabe ressaltar que a maior parte dos participantes da pesquisa são mulheres, sendo que, tendo em vista a sociedade patriarcal brasileira, foi possível perceber o 


\section{OO DEVIR EDUCAÇÃO}

ISSN: 2526-849X

quanto as mulheres se sentem responsáveis pela saúde da família, principalmente na pandemia, a qual sobrecarregou o trabalho destas.

Os resultados indicaram que não importa em qual rede de ensino ou etapa de ensino atue, seja homem ou mulher, mais ou menos jovem, todos estão muito preocupados com a sua saúde física e mental e quanto maior for a cidade em que mora, aumenta mais a preocupação. Tal nível de preocupação gera estresse, ansiedade e impacta diretamente a atuação profissional do professor.

Sobre as ações que os participantes consideram como prioritárias neste momento, tornou-se evidente a dinamicidade destes com relação à condição estrutural geral da escola, que talvez, pode ser travada por processos burocráticos não tão propulsores da eficácia de certas condutas educacionais. Mas ainda assim, foi possível captar a existência de oferta de capacitação profissional para com o formato remoto aos professores e são eles que se dispõem a buscar esses mecanismos a fim de melhorar sua prática pedagógica. A priorização do trabalho foi uma realidade para professores de todos os níveis, etapa de ensino, unidade federativa ou idade. Esses resultados acentuam o compromisso e a consciência profissional dos (as) professores (as).

A despeito de todas as vicissitudes da novidade de trabalho, os (as) professores (as) ainda se sentem realizando um bom trabalho. Mesmo diante de tantos desafios enfrentados, estes (as) ainda mostram otimismo quanto sua atuação neste momento atípico, pressupõe-se que, mesmo com ausência de capacitação profissional, os professores percebem que estão atendendo às novas formas de atuar, exigidas pela instituição de ensino e pela circunstância do momento. Essa investigação com professores dos municípios de Formosa e São Paulo constatou a resiliência dos professores em ainda manterem um resquício de otimismo frente às adversidades.

A autoavaliação do/da docente frente à experiência com o ensino remoto foi um aspecto que se apresentou homogêneo mediante todas as variáveis, sem diferença significativa, ou seja, variáveis que perpassam a idade, sexo, cidade e estado em que reside, rede de ensino em que trabalha, etapas de ensino com que atuou ou atua não tiveram diferença significativa. A amostra partilha necessidades similares independente de gênero idade, etapas ou rede de ensino e unidade federativa, quanto ao apoio financeiro, psicológico e técnico. Constata-se, pois, que por mais que o século atual seja movido pelas redes sociais e internet, usar essa ferramenta para transmitir conhecimento não é tão fácil assim, ainda mais quando se 


\section{QD DEVIR EDUCAÇÃO \\ ISSN: 2526-849X}

trata de profissionais não preparados para executar tal ação. Contudo é possível que após o período pós-pandemia, o ensino remoto e o uso de tecnologias aliado ao aumento da carga horária poderão ser incorporados ao contexto escolar a fim de dirimir as consequências de tão longa interrupção do calendário escolar. Ao escolher entre alternativas seguras para a aprendizagem dos nossos estudantes. Como ressalta Honorato (2021) devemos nos perguntar não apenas como superar a ameaça imediata, mas também que tipo de mundo habitaremos quando a tempestade passar.

A realização desta pesquisa insere-se dentro da modalidade de pesquisa científica, e espera-se que os resultados gerem novos conhecimentos que possam minimizar os efeitos negativos da pandemia da covid-19 no cenário educacional, bem como compreender o que professores vivenciaram em sua prática pedagógica, concomitante abre outras frentes de estudo como expectativas no pós pandemia; inclusão escolar, alfabetização, abandono escolar, relações étnico raciais e outros.

\section{Referências}

BRASIL. Portaria n ${ }^{\circ}$ 343, de 17 de março de 2020. Diário Oficial da República Federativa do Brasil. Edição:53.Seção: 1. Página: 39. Disponível em https://www.in.gov.br/en/web/dou/-/portaria-n-343-de-17-de-marco-de-2020-248564376 . Acesso em 21 out, 2020.

DIAS, Eika.; PINTO, Fatima Cunha Ferreira. A Educação e a Covid-19. Ensaio: aval. pol. pub. Educ., Rio de Janeiro, v.28, n.108, p. 545-554, 2020.

FAZENDA, Ivany.; TAVARES, Dirce.; GODOY, Herminia Prado. Interdisciplinaridade na pesquisa científica. Livro digital: Papirus, 2015Fazenda

FELTRIN, Tascieli; BATISTA, Nathalia Lmpert. Autoformação docente em tempos de pandemia: da (im)possibilidade da reinvenção sem cuidado de si. Revista Científica Educ@ção v.4 • n.8 • outubro/2020

FUNDAÇÃO CARLOS CHAGAS. Educação escolar em tempos de pandemia na visão de professoras/es da Educação Básica, São Paulo, junho/2020. Disponível em <\&lt;https://www.fcc.org.br/fcc/educacao-pesquisa/educacao-escolar-em-tempos-depandemia-informe-n-1\&gt; > acesso em 16 ago, 2020.

GOTTI, Eduardo Souza; et al. Ativação em casa: princípios de ativação comportamental para minimização dos efeitos do isolamento social. Revista brasileira de análise do comportamento / brazilian journal of behavior analysis, Vol. 16, N.1, 41-49. 2020. 
HACKENAAR, Andreia Souza; GRANDI, Deise. Breves reflexões acerca da educação local durante a pandemia. In: PALÚ, Janete.; SCHÜTZ, Jenerton Arlan.; MAYER, Leandro. Desafios da Educação em tempos de pandemia. Cruz Alta - RS: Ilustração, 2020.

HONORATO, Hercules Guimarães. Os meandros da educação e da aprendizagem em meio à pandemia covid-19: os desafios e as lições. REVES -Revista Relações Sociais, Vol. 04 N. 01 2021.

INEP - Instituto Nacional de Estudos e Pesquisas Educacionais Anísio Teixeira. Censo Escolar, 2019. Brasília: MEC, 2019.

LAMIM, João Eduardo; NASCIMENTO, Sandro Everton; CORDEIRO, Edvando Santos.

Condições do trabalho docente durante as aulas remotas: desafios educacionais pós-pandemia. ReDiPE: Revista Diálogos e Perspectivas em Educação, Marabá-PA, v.2, n. 2,p. 354364,jul.-dez. 2020

LIMA, Marcelo de Oliveira.; VIANA, Giselle Maria Rachid. Divulgação científica: responsabilidade e importância. Revista Pan-Amazônica de Saúde, v. 8, n. 4, p. 7-8, dez, 2017.

MACEDO, Renata Mourão. Direito ou privilégio? Desigualdades digitais, pandemia e os desafios de uma escola pública. Estudos Históricos, Rio de Janeiro, vol 34, nº 73, p.262-280, Maio-Agosto 2021.

MOREIRA, Daniela Zanoni; RODRIGUES, Maria Beatriz. Saúde mental e trabalho docente. Estud. psicol. (Natal) vol.23 no.3 Natal jul./set. 2018

ONU MULHERES. Gênero e Covid-19 na América Latina e no Caribe: dimensões de gênero na resposta. ONU Mulheres, mar. 2020. Disponível em: http://www.onumulheres.org.br/ Acesso em: 24 jun. 2021

OLIVEIRA, Vanuza Cecilia. et al. De repente 4.0: Mudanças de paradigma educacional em tempos de pandemia. In: PALÚ, Janete.; SCHÜTZ, Jenerton Arlan.; MAYER, Leandro. Desafios da Educação em tempos de pandemia. Cruz Alta - R.S: Ilustração, 2020.

OPAS - Organização Pan-Americana da Saúde. Folha informativa COVID-19 - Escritório da OPAS e da OMS no Brasil, outubro de 2020. Disponível em https://www.paho.org/pt/covid19. Acesso em 07 mar.2021.

PALU, Janete. A crise do capitalismo, a pandemia e a educação pública brasileira: reflexões e percepções. In: PALÚ, Janete.; SCHÜTZ, Jenerton Arlan.; MAYER, Leandro. Desafios da Educação em tempos de pandemia. Cruz Alta - Rio Grande do Sul: Ilustração, 2020.

PEREIRA, Hortência Pessoa; SANTOS, Fábio Viana; MANENTI, Mariana Aguiar. Saúde Mental de Docentes em Tempos de Pandemia: Os Impactos das Atividades Remotas. Boletim de Conjuntura (BOCA), Boa Vista - RR, v.3, n.9, p.26-32, 2020. 


\section{QD DEVIR EDUCAÇÃO \\ ISSN: 2526-849X}

RAMBO, Nestor Francisco. A educação em rede em época de pandemia e pós-pandemia: In: PALÚ, Janete.; SCHÜTZ, Jenerton Arlan.; MAYER, Leandro. Desafios da Educação em tempos de pandemia. Cruz Alta - Rio Grande do Sul: Ilustração, 2020.

SCHNEIDRS, Carlise. O ensino da história no ensino fundamental II em um contexto pandêmico: relato de experiência. In: PALÚ, Janete.; SCHÜTZ, Jenerton Arlan.; MAYER, Leandro. Desafios da Educação em tempos de pandemia. Cruz Alta - Rio Grande do Sul: Ilustração, 2020.

SILVA, Luiz Alessandro; PETRY, Zaida Jerônimo Rabello; UGGIONI, Natalino. Desafios da educação em tempos de pandemia. In: PALÚ, Janete.; SCHÜTZ, Jenerton Arlan.; MAYER, Leandro. Desafios da Educação em tempos de pandemia. Cruz Alta - Rio Grande do Sul: Ilustração, 2020. Disponível em www.sed.sc.gov.br. Acesso em Acesso em 17, jul. 2021.

SILVA, Juliana, Marcia Santos, et al. A feminização do cuidado e a sobrecarga da mulhermãe na pandemia. Revista femininos. Vol.8, N.3, Set. - Dez. 2020.

UNICEF - Fundo das Nações Unidas para a Infância. Cenário da Exclusão Escolar no Brasil: Um alerta sobre os impactos da pandemia da COVID-19 na Educação. Abril de 2021. Disponível em https://www.unicef.org/brazil/ acesso em 27 jun, 2021.

ZAIDAN, J. M.; GALVÃO, A. C. "COVID19 e os abutres do setor educacional: a superexploração da força de trabalho escancarada". In: AUGUSTO, C. B.; SANTOS, R. D. (orgs.). Pandemias e pandemônio no Brasil. São Paulo: Instituto Defesa da Classe Trabalhadora, 2020.

Recebido em: 01/07/21

Aprovado em: 28/08/21 